\title{
Cross-Cultural Communication Patterns In Computer Mediated Communication
}

Daria Panina, Ph.D., Texas A\&M University, College Station, USA

Maya Kroumova, Ph.D., New York Institute of Technology, USA

\begin{abstract}
There are important cultural differences in attitudes towards and use of electronic text communication. Consistent with Hall's high-context/low-context conceptualization of culture, electronic inter-cultural communication, just as verbal inter-cultural communication, is affected by the culturally-specific assumptions and preferences of message writers.
\end{abstract}

Keywords: Cross-cultural Communication Patterns; Computer Mediated Communication

\section{INTRODUCTION AND LITERATURE REVIEW}

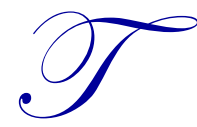

he purpose of this paper is to address the gap in current knowledge concerning the impact of culturally-bound communication styles on electronic communication. In particular, we focused on electronic mail as it is still the most prevalent form of computer mediated communication used in organizations today (Dirks \& Bakker, 2010). We used Hall's (2003) theoretical framework about communication context to analyze differences in communication styles and generate hypotheses about electronic communication.

The communication styles of people from different cultures range from explicit to ambiguous, forming a bipolar low/high context continuum (Hall, 2003). Low-context communication primarily relies on explicit and direct verbal messages, whereas high-context communication relies more on the physical and cultural context of the communication process rather than on the content of the message itself.

A culture's dominant communication styles are linked to cultural values. People from collectivistic cultures tend to use high-context communication to preserve harmony in their groups (Gudykunst et al., 1996) and maintain the face of oneself and others. Communication in collectivist cultures is associated with interpersonal sensitivity, perceived ability to infer the feelings, intentions and needs of others, and preference for indirectness (e.g., Bargiela-Chiappini, 2003; Holtgraves, 1997, 1998). People from cultures where individualist values are dominant tend to assume a functional and task-oriented approach to communication. Individualistic cultures are associated with open and precise communication, conversational accuracy, and clarity (Hara \& Kim, 2004).

One of the most obvious differences between high-context and low-context communication styles is the amount of verbal output in conversations. When a large part of the message is encoded in the communication context, the need to explain everything with words is low (Hall, 2003). We hypothesize that, as in face-to-face communication, messages written by individuals from low-context cultures will convey more information through words, and therefore be longer than messages written by individuals from high-context cultures.

Hypothesis 1: Individuals from low-context cultures will write e-mails that are longer than the e-mails written by individuals from high-context cultures.

Two other features that distinguish high-context from low-context communication are vagueness and politeness. High-context communication is more vague than low-context one, because vagueness serves as a politeness strategy and helps interlocutors preserve harmony. For example, Sunaoshi (2005) found that Japanese workers were less direct in their communications with American counterparts, to the point where Americans were" never completely sure if the Japanese had understood when they said yeah" (p. 194). Similar differences were found 
in the communication styles of U.S. and Arabic cultures (Levine, 1985). High-context cultures are known for indirectness in the composition of conventional written messages such as letters: they allow message to develop gradually in a roundabout manner and get to the point towards the end (Campbell, 1998). Several studies have found that due to their collectivist orientation, individuals from Asian and Arab cultures are likely to be more polite than individuals from low-context, individualist cultures in both verbal and written communications (e.g., Feghali, 1997; Park et al., 2005). Therefore, we hypothesize that this tendency towards indirectness and politeness will carry over to computer mediated communication as well:

Hypothesis 2: Individuals from low-context cultures will write e-mails that are perceived as more direct than the emails written by individuals of high-context cultures, from the perspective of individuals from low-context cultures.

Hypothesis 3: Individuals from high-context cultures will write e-mails that are perceived as more polite than the emails written by individuals of low-context cultures, from the perspective of individuals from low-context cultures.

Members of high-context, collectivist cultures are considered to be more concerned about relationships than tasks, and thus may be expected to be more polite as compared to the more task-oriented members of individualist cultures. However, the lack of directness and the emphasis on politeness may diminish the effectiveness of the message being communicated:

Hypothesis 4: Messages written by individuals from low context cultures will be perceived as more effective compared to messages written by individuals of high context cultures, from the perspective of individuals from lowcontext cultures.

\section{METHOD}

Participants for this study were recruited among Japanese, American, and Jordanian undergraduate students attending US universities. A total of 183 students participated in this study, of which 125 were American, 32 Jordanian, and 25 Japanese.

The participants in the study were asked to read a hypothetical situation, which was developed by Cocroft and Ting-Toomey (1994) specifically to test the communication behaviors of people from high-context and lowcontext cultures. The hypothetical situation used asks participants to imagine their classmate asked them for a favor (borrow a textbook from a professor); once the classmate gets the book, he/she does no return it on time, despite the participant's initial request. After reading this hypothetical scenario, participants were asked to state their preferred channel of communication to handle this conflict, but then imagine that the only way to reach the other student was by electronic mail. They were then asked to write an e-mail message requesting the return of the book. The scenario was presented in English, and the e-mail was also to be composed in English.

We asked four American raters to evaluate a subsample of 56 e-mails on three dimensions - politeness, clarity, and effectiveness. The raters were undergraduate US students taking a business course at a large southern US university. They were provided rating instructions, and were presented the emails to rate in a random order. Raters were unaware of the message writer's nationality.

\section{Communication Quantity and Quality}

The volume of communication was measured by the length of the message, i.e., the number of symbols it contains. The directness and politeness_of the e-mails were evaluated by 4 American raters using one 5-point Likert type scale (e.g. Very unclear $=1$, Very clear $=5$ ) for each of these variables. Effectiveness was operationalized as the rater's likelihood to comply with the request expressed by the writer (on a scale of 1 to 5). The raters were undergraduate students at a US university. We randomly varied the order in which the raters read the e-mails to avoid bias. 


\section{Control Variables}

We measured conversational indirectness preferences, self-reported English proficiency, and gender for each subject. Conversational indirectness was measured using the Conversational Indirectness Scale (Holtgraves, 1997), in order to make sure that participants in the study possessed the dominant communication styles of high context or low context cultures.

\section{RESULTS}

We conducted confirmatory factor analysis to ascertain that our subjects had communication directness preferences consistent with theory and prior research. The Jordanian and Japanese samples demonstrated a high preference for producing indirect meaning, and the US sample had, as expected, the lowest preference to do that. Descriptive statistics are reported in Table 1.

Table 1

\begin{tabular}{lcc|cc}
\hline & & Model 1 & \multicolumn{2}{c}{ Model 2 } \\
\hline IVs & Coefficient & Std. Error & Coefficient & Std. Error \\
\hline Japanese & & & -97.79 & $46.19^{* *}$ \\
Jordanian & & & -96.15 & 63.85 \\
Gender & -62.10 & $22.47 * * *$ & -52.11 & $23.00^{* *}$ \\
English Proficiency & 26.10 & $7.42^{* * *}$ & 8.99 & 11.23 \\
Intercept & 213.60 & $65.43 * * *$ & 311.30 & $79.57 * * *$ \\
R Square & 0.17 & & 0.20 & \\
F test & $7.16^{* * *}$ & & $5.62 * * *$ & 141 \\
N & 141 & & & \\
\hline
\end{tabular}

Additional control variables included familiarity with the culture of the message recipient, and perceived cultural distance between the message writer and recipient; the coefficients for these were not statistically significant, and are not reported here. $* \mathrm{p}<0.1, * * \mathrm{p}<0.05, * * * \mathrm{p}<0.01$

Message length varied across high context and low context cultural groups (descriptive statistics are available from the authors). The regression analysis reported in Table 1 shows that Japanese subjects wrote e-mails that were about $35 \%$ shorter compared to US subjects, and this difference in message length was significant at the 0.05 level. Jordanian e-mails were $25 \%$ shorter compared to US e-mails, but the difference, although in the expected direction, was marginally significant $(\mathrm{p}=0.13)$. Of the control variables, gender had a significant relationship with message length, with men writing shorter e-mails than women. These results provide partial support for Hypothesis 1. The Japanese sample behaved as expected, and although the Jordanian participants did not differ from US students in terms of message volume, further qualitative analysis of their e-mails' content suggested that message length was driven by different factors in these cultures. Messages written by US respondents tended to be long because they contained a lot of specific information, whereas messages written by Jordanian participants tended to be long because they contained a lot of roundabout politeness.

Hypothesis 2 received some support. The results were in the expected direction (see Table 2), but the mean differences in perceived clarity between high context and low context cultural groups are statistically significant at the 0.10 level. Hypothesis 3 was partially supported - Jordanian e-mails were perceived, on average, as more polite than US e-mails; however, Japanese e-mails were not (see Table 2). 
Table 2

\begin{tabular}{|c|c|c|c|c|}
\hline \multicolumn{5}{|c|}{ DV: Perceived Message Politeness } \\
\hline IVs & Coefficient & Std. Error & Coefficient & Std. Error \\
\hline Intercept & 4.45 & $0.26 * * *$ & 2.64 & 0.87 \\
\hline Japanese & -0.73 & $0.37 *$ & 0.64 & 0.57 \\
\hline Jordanian & -0.67 & $0.37 *$ & $\begin{array}{l}1.66 \\
\text { Yes }\end{array}$ & $0.79 * *$ \\
\hline R Square & 0.08 & & 0.28 & \\
\hline F test & 2.41 & $*$ & 3.06 & $* *$ \\
\hline $\mathrm{N}$ & 56 & & 54 & \\
\hline
\end{tabular}

${ }^{*} \mathrm{p}<0.1 ; * * \mathrm{p}<0.05 ; * * * \mathrm{p}<0.01$; The dependent variables are regressed on a set of dummy variables representing the 3 cultures. The omitted category is the American sample.

Hypothesis 4 was supported. It was tested using a regression model similar to the one for hypotheses 2 and 3. The results from regressing perceived effectiveness on cultural group dummies ( $\mathrm{R}$ square $=0.10, \mathrm{~F}=2.93$, $\mathrm{p}=0.062$ ) indicated that the messages written by Japanese participants (coefficient $=-0.58, \mathrm{p}=\mathrm{p} .10$ ) and Jordanian participants (coefficient $=-0.81, \mathrm{p}=0.03$ ) were rated as less effective than those written by US writers (average effectiveness of 4.25 on a scale of 1 to 5) by the 4 American raters used in this study.

\section{DISCUSSION}

Our results indicated that cultural differences in communication styles do carry over to electronic communication. As expected, low-context communicators wrote e-mails that were relatively longer, clearer, and less polite (as perceived by low-context raters), compared to the e-mails generated by communicators from the two high-context cultures studied. The results for high-context communicators uncovered interesting differences that call for further research. Participants from the two high-context cultures studied, Japanese and Jordanian, used different communication strategies. Future research might benefit from more refined models of culturallydetermined communication patterns and preferences.

Our study has several limitations. Our samples of Japanese and Jordanian respondents were small. Also, we used one particular type of communication scenario, so it is difficult to generalize to other communication situations in general. Finally, as with all research using undergraduate students, it is difficult to generalize their behaviors to the population of all multinational company employees, although they may be similar to entry-level employees.

\section{AUTHOR INFORMATION}

Daria Panina, Ph.D., Department of Management, 4221 Texas A\&M University, College Station, TX 77843-4221, USA. Tel: (979) 845-4848; Email: dpanina@cgsb.tamu.edu

Maya Kroumova, Ph.D., (Corresponding Author), School of Management, New York Institute of Technology, 1855 Broadway, New York, NY 10023, USA. Tel: (212) 261 1667; Email: mkroumov@nyit.edu

\section{REFERENCES}

1. Bargiela-Chiappini, F. (2003). Face and politeness: New (insights) for old (concepts). Journal of Pragmatics, 35, 1453-1469.

2. Campbell, C.P. (1998). Where culture and rhetoric meet: contrastive rhetoric. Paper presented at Region 5 STC Conference, Fort Worth, Texas.

3. Cocroft, B.-A., \& Ting-Toomey, S. (1994). Facework in Japan and the United States. International Journal of Intercultural Relations, 18, 4, 469-506.

4. Dirks, D., \& Bakker, A. (2010) The Impact of Electronic Communications on Organizational Life. Cyberpsychology: Journal of Psychosocial Research on Cyberspace, 4(1).

5. Feghali, E. (1997). Arab cultural communication patterns. International Journal of Intercultural Relations, 21(3), 345-378. 
6. Gudikunst, W.B., Matsumoto, Y., Ting-Toonmey, S., Nishida, T., Kim, K., \& Heyman, S. (1996). The influence of cultural individualism-collectivisms, self-construals, and individual values on communication styles across cultures. Human Communication Research, 22, 510-543.

7. Hall, E.T. (2003) Beyond culture. New York, NY: Anchor Books.

8. Hara, K., \& Kim, M. S. (2004). The effect of self-construals on conversational indirectness. International Journal of Intercultural relations, 28, 1-18.

9. Holtgraves, T. (1997). Styles of language use: Individual and cultural variability in conversational indirectness. Journal of Personality and Social Psychology, 73, 3, 624-637.

10. Holtgraves, T. (1998). Interpersonal foundations of conversational indirectness. In S.R. Fussell, \& R.J. Kreuz (Eds.), Social cognitive approaches to interpersonal communication (pp. 71-89). Mahwah, NJ: Lawrence Associates.

11. Levine, D. (1985). The flight from ambiguity. University of Chicage Press, Chicago, IL.

12. Louhiala-Salminen,L. \& Kankaanranta, A. (2012) Language as an issue in international internal communication: English or local language? If English, what English?, Public Relations Review, 38(2), 262269.

13. Park, H.S., Lee, H. E., \& Song, J.A. (2005). "I am sorry to send you SPAM": Cross-cultural difference in use of apologies in email advertising in Korea and the U.S. Human Communication Research, 31(3), 365398.

14. Sunaoshi, Y. (2005). Historical context and intercultural communication: Interactions between Japanese and American factory workers in the American South. Language in Society, 34, 185-217.

15. Ting-Toomey, S. (1994). Face and facework: An Introduction. In Ting-Toomey (Ed.). The Challenge of Facework. Albany: State University of New York Press. 


\section{NOTES}

